\title{
Machining response of Ti64 alloy under Nanofluid Minimum Quantity Lubrication (NFMQL)
}

\author{
Sarthak Prasad Sahoo ${ }^{1 *}$ and Saurav Datta ${ }^{1}$ \\ ${ }^{1}$ Department of Mechanical Engineering, National Institute of Technology, Rourkela-769008, Odisha (India)
}

\begin{abstract}
Rapid wear progression of cutting insert associated with attainment of excessive tool-tip temperature are indispensable causes which limit operational domain of cutting velocity during dry turning of Ti64 alloy. Again, to counteract demerits of flood cooling, jet of air-oil mist (MQL technology) is employed in which water-based coolants or vegetable oils are highly preferable. On the other hand, inclusion of nano-additives within base fluid, and supply the same through MQL system (NFMQL) is also a trendy area of research. Application potential of NFMQL is understood over conventional MQL in terms of better cooling, and lubrication effects due to improved thermo-physical, and tribological properties of the resultant cutting fluid. In this context, present study aims to assess performance of MQL jet containing biodegradable Jatropha oil (carried by pressurized air) when applied during longitudinal turning of Ti64 work alloy. In addition, advantages of 2D layered-structured graphene nanoplatelets (when dispersed into Jatropha oil), in purview of machining performance on difficult-to-cut Ti64 alloy under NFMQL, are studied in this work. Experimental data are compared on the basis of different lubrication conditions (dry, conventional MQL, and NFMQL). Morphology of tool wear is studied in detail. The work extends towards studying chip morphology and machined surface finish of the end product, as influenced by variation in lubrication conditions.
\end{abstract}

\section{Research background}

In purview of industrial applicability, assessment of machinability of any work material is indeed necessary. Extent of machinability is influenced by properties of workpiece, properties as well as geometrical features of the cutting tool, type of machining operation to be carried out, cutting environment, and rigidity of the machine tool. Recent developments of advanced materials along with their outstanding physical/ mechanical properties drive manufacturing sectors to seek for appropriate strategies for economic material processing. With the ability to retain strength at elevated temperatures, and to form a tight film of tenacious oxide when exposed to atmosphere (in order to hinder attack by corrosive agents), titanium alloys maintain a superior position in the global market which leave behind traditionally used structural steels, cast irons etc. From amongst commercially available titanium alloys, grade5 alloy (Ti6Al4V or Ti64), which is basically a biphased alloy, is extensively used in fields of aerospace, marine, and oil refineries [1]. Also its corrosion resistivity, excellent bio-compatibility, and lower elastic modulus (when compared to stainless steel and cobaltbased alloys) make this alloy very attractive for diversified biomedical applications [2]. Still, machining of this alloy is, however, considered as a challenging task as described in the literature [3].

In their work, Dearnley and Grearson [4] pointed out that carbide grades cutting tools, generally used for machining of steel, could not provide desirable results for titanium machining; rather a straight grade $(K$ grade) cemented carbide (with grain size not less than $0.8 \mu \mathrm{m}$ ) embedded with cobalt binder (of $6 \%$ by weight) could fulfil the purpose. Many research groups [5-9] attempted machining operations (continuous as well as intermittent) on Ti64 workpieces, under dry environment. It was experienced that employed cutting tools went through rapid wear progression by shortening tool life as huge amount of machining induced heat got accumulated at the tool-tip. This also resulted in dissatisfactory surface quality of machined specimen, and, hence, limited the cutting speed values.

In their 'Keynote Papers', Klocke and Eisenblatter [10] stated that during continuous high speed machining of titanium alloys, it is necessary to employ cutting fluid (or coolant) along with a carbide cutting tool. Application of cutting fluid during machining can be broadly referred as wet machining or machining under flood cooling. The studies [11-12], no doubt, witnessed merits of wet machining over traditional dry cutting as the tool-tip temperature was found to be lowered much

*Corresponding author: sdattaju@gmail.com 
which, in turn, caused extended tool life as well as substantially improved machined work part surface integrity.

But, cost of machining was found to be increased with wet machining due to huge consumption of cutting fluids. The post-use disposal of conventionally used mineral oils/ synthetic oil based coolants also added to the machining cost. In addition, Lazarus [13] found that used coolants of aforementioned types were not ecofriendly. Thus, researchers tried for viable alternatives of wet machining which could reduce cutting fluid consumption [14]. Amongst them, (Minimum Quantity Lubrication) MQL was found to be much efficient for industrial applications as it uses an optimal amount of coolant with compressed gas carrier. Therefore, with MQL technology, elevated cost of cutting fluids, and their post-usage disposal problem could be minimized. On the other hand, the air-oil mist generation during wet machining and MQL-assisted machining at the machining centre was reported to cause occupational health hazards for machine operators [15]. In addition, MQL-jet, often, fails to properly lubricate core machining sites, especially, during high speed machining (due to inadequate penetration into tool-chip/ tool-work interfacial zones). In order to ensure effective penetration of cutting fluid, and thus, better lubricating effect; conductive nano-sized additives are dispersed within the base cutting fluid. The resultant coolant is popularly known as nanofluid; since, applied with MQL, the technology is denoted as NFMQL (nanofluid MQL).

As mentioned by Byers [16], water based coolants had better usability for machining of titanium alloys due to easy availability, low cost, and high heat transfer capability. While machining Ti64, Setti et al. [17] dispersed $\mathrm{Al}_{2} \mathrm{O}_{3}$ and $\mathrm{CuO}$ nano-particles (with varying concentration) with water, and revealed beneficial effects of resultant nanofluids in terms of reduced friction coefficient, and C-type chip formation (due to effective cooling). Also, in a review article, Sharma et al. [18] compared properties of different cutting fluids from machining viewpoint; merits of vegetable based oils over others due to their higher viscosity index, higher flash point, good lubricity properties, and higher biodegradability etc. were discussed. Songmei et al. [19] prepared four different types of nanofluids with natural77 vegetable oil by dispersing nano-particles of $\mathrm{MoS}_{2}$, $\mathrm{Al}_{2} \mathrm{O}_{3}$, graphite, and $\mathrm{Cu}$, respectively, in $1 \%$, and $2 \%$ of volume fractions. These nanofluids were applied during milling of Ti64. Reduced cutting force and lower surface roughness of the machined product were witnessed with nanofluids having $\mathrm{Cu}$, and graphite nano-particles. Issues related to occupational health hazards were substantially reduced by applying such biodegradable vegetable oil based nanofluids.

Many authors [20-23] also revealed merits of both Single-Walled Carbon Nanotubes (SWCNTs), and Multi-Walled Carbon Nanotubes (MWCNTs), when used as additives to prepare nanofluids for steel machining applications, in terms of less thermal distortions, improved thermal conductivity, and increased heat carrying capacity. However, few research groups [24-26] studied performance of nanofluids by dispersing MWCNTs in water as well as vegetable oils, during machining of Ti64 alloy.

Samuel et al. [27] prepared a semi-synthetic metal working fluid by mixing graphene platelets (GP) of varied concentration in Castrol Clearedge 6519 oil, and used for micro-machining of 1018 steel with a Cubic Boron Nitride (CBN) tool. GP-added nanofluid performed better than other two nanofluids (containing SWCNTs, and MWCNTs, as additives) in terms of cooling, and lubrication effects at the machining zone. Uysal [28] carried out MQL-milling on AISI 430 stainless steel by introducing nano-graphene particles within Eraoil KT/2000 with uncoated as well as coated carbide inserts. Lower tool flank wear rate, and lesssevere rake face wear were witnessed with nano-particle added MQL system. Yi et al. [29] prepared nanofluid by adding nano-structured graphene oxide with ROCOL ultracut clear oil, and applied the same for turning of Ti64 using a Polycrystalline Cubic Boron Nitride $(\mathrm{PcBN})$ cutting insert. Significant reduction in cutting force as well as cutting zone temperature was witnessed due to application of nanofluid. Again, research groups [30-31] highlighted performance characteristics of a vegetable oil called Jatropha oil in MQL system, and recommended as a viable alternative for metal working fluid.

Though a few research groups applied MWCNT (dispersed in vegetable oils) based nanofluids during machining of Ti64; feasibility of using graphene powder, as nano-additives, is yet to be explored adequately in the context of NFMQL machining on the same work alloy. In addition, performance of nanofluid with biodegradable Jatropha oil is also an unexamined area with regard to machining under lubrication. Vegetable oil based coolants stand as a viable alternative against conventionally used mineral oils [13]. Thus, demand for vegetable oils is increasing day-by-day. Indeed, usage of vegetable oils as industrial coolant application can also affect market demand (in food sector) which is difficult to meet. Thus, usage of nonedible vegetable oils, as industrial coolants, is very much preferable, and Jatropha oil satisfies all these requirements. Aforementioned aspects in relation to Jatropha oil are, however, elaborately highlighted in literatures by Bilal et al. [32], and Sarkar [33].

In this work, dry machining, and machining under conventional MQL with Jatropha oil is carried out on Ti64 workpiece. Also, application potential of nanofluid, prepared by dispersing graphene nanoplatelets within Jatropha oil is also studied.

\section{Experimental details}

All experimental trails for the present study are performed on a heavy duty precision lathe (NH26, HMT Machine Tools Limited, Bengaluru). A $460 \mathrm{~mm}$ long workpiece of Ti64 (Ti-6Al-4V) with cross-section $\varphi 55$ $\mathrm{mm}$ is used herein. $K$-graded uncoated tungsten carbide (WC-Co) insert with ISO designation SNMG120408 is used to perform longitudinal turning operations. This insert is held with a PSBNR-2020K12 type tool holder 
(Kennametal) which ensures an approach angle of $75^{\circ}$, rake angle of $-6^{\circ}$, and inclination angle of $-6^{\circ}$. The said insert has nose radius of $0.8 \mathrm{~mm}$. A lubrication system (MLE-OMS-1500, Masterlube Engineers, Mumbai) is employed to supply pressurized jet of air-oil mist. For providing cooling as well as lubrication, biodegradable Jatropha oil is used as base cutting fluid both for MQL, and NFMQL machining. Beneficial chemical, and physical properties of Jatropha oil (as a cutting fluid) was already documented by Sarker [33]. Graphene nanoplatelets (procured from Platonic Nanotech Private Limited, Jharkhand) are dispersed (with $0.1 \%$ by weight) into the base cutting fluid (without surfactant) for further use as nanofluid. Aforesaid concentration of graphene is finalized based on literature survey [34-35]. Specifications of as received graphene powder are: Purity: >99\%, Length: 5-10 nm, Density: $0.15 \mathrm{~g} / \mathrm{cc}$, Average number of layers: 4 to 8, and Surface area: 190 $\mathrm{m}^{2} / \mathrm{g}$. Important properties of graphene are: Thermal conductivity: $3000 \mathrm{Wm}^{-1} \mathrm{~K}^{-1}$, Electrical conductivity: $10^{7} \mathrm{~S} / \mathrm{m}$, and Tensile modulus: $>1000 \mathrm{GPa}$.

Mixing of nano-additives with base fluid is accomplished in two stages: firstly, through a magnetic stirrer with heating capacity of $500 \mathrm{~W}$ (5 MLH, REMI Laboratory Instruments, Mumbai) for about $55 \mathrm{~min}$ stirring, and secondly, through an ultrasonic frequency assisted bath cleaner (LMUC4, LABMAN Scientific Instruments Pvt. Ltd., Chennai) for about $70 \mathrm{~min}$ agitation. Settling time of the prepared nanofluid is predicted to be $2-3 \mathrm{~h}$, after completion of mechanical dispersion.

Machining trials are carried out under dry (without lubrication), conventional MQL, and NFMQL conditions. In consideration with each of the cutting environments, four trial passes are carried out at varied cutting velocities $(v=50 \mathrm{~m} / \mathrm{min}, v=80 \mathrm{~m} / \mathrm{min}, v=$ $100 \mathrm{~m} / \mathrm{min}$, and $v=120 \mathrm{~m} / \mathrm{min})$; but, constant depthof-cut $(\sim 0.35 \mathrm{~mm})$, and constant feed $(\sim 0.1 \mathrm{~mm} / \mathrm{rev})$ are maintained. Duration for each machining trial is also kept constant $(\sim 30 \mathrm{~s})$. A fresh cutting edge is used in each trial.

For machining under lubrication, flow rate, and pressure of the jet are maintained at $2.4 \mathrm{ml} / \mathrm{min}$, and 4 bar, respectively [36]. The MQL nozzle is kept at a distance $5 \mathrm{~cm}$ from the tool-tip. The jet coming from the nozzle makes $45^{\circ}$ angles with perpendicular to the tool insert. Optical microscope (Carl Zeiss Microscopy, GmbH 37081 Gottingen, Germany), Scanning Electron Microscope (SEM) (JSM 6480 LV, Jeol, Japan), and Field Emission Scanning Electron Microscope (FESEM) (Nova NanoSEM 450, FEI, USA) are used for detailed assessment of tool wear, chip morphology, and machined surface finish. EDS facility integrated with SEM setup is utilized for elemental analysis.

\section{Results and discussion}

As comes under the category of difficult-to-cut material, machining of Ti64 is always associated with high cutting zone temperature due to its inherent poor thermal conductivity. The work alloy's hot strength and intense work-hardening tendency necessitate high cutting force. Cutting force magnitude and cutting zone temperature directly influence wear progression of the cutting insert which, in turn, influences machined surface integrity. As the considered work material has crucial applications under sophisticated operating environments, machined surface finish is an interesting area of concern. In order to predict machining effects on Ti64, morphology of the machined surface is analysed herein. Qualitative assessment on micro-morphology of the generated surface is carried out through Fig. 1. Fig. 1 represents micrographs of machined surfaces generated at $v=80$ $\mathrm{m} / \mathrm{min}$, under varied lubrication conditions. Machining of Ti64 without any lubrication (dry condition) produces surfaces with prominent feed marks, traces of side flow of material, along feed marks (Fig. 1a). Reason behind this observation can be related to huge flank wear of the carbide insert due to excessive heat accumulation at the tool-tip, and high magnitude of cutting force than other two lubrication conditions [37]. Also, fragments of evolved chips are found stuck on the surfaces which are already oxidized due to availability of atmospheric oxygen, and machining induced heat at the chip surface. Better surface quality (as compared to dry machining) is witnessed during MQL machining as shown in Fig. 1 b. Reduced temperature at the tool-tip, due to pressurized fluid flow, lowers wear progression of the cutting insert, and thus, less surface defects are pronounced. At times, wear debris carried out by the coolant from the machining zone gets deposited on the machined surface which is known as smeared materials [38]. Also, carbide cracking at the machined surface (due to high depth-ofcut) can produce such smeared material which was described by Ulutan and Ozel [39]. The smoothest surface, amongst all lubrication condition tested, is achieved under NFMQL machining (Fig. 4c). Minimal extent of machining induced heat at the tool-tip due to better cooling capability (as compared to MQL), and lower friction coefficient at the tool-work/ tool-chip interfaces (due to tribological benefits of graphene sheets) are solely responsible for such a betterment of machined surface quality. Hardly, tiny micro-pores are evidenced on the machined surface which can be attributed to entrapment of harder inclusions (produced at machining zone) onto the machined surface. Thus, better integrity of the machined surface is attained with the MQL jet with dispersed nano-additives.

Next, detailed investigation on different wear modes are carried out through scanning electron microscopy of worn-out tool inserts. Figs. 2-5 describe dominant wear modes along with obvious flank wear, and crater wear, as suffered by the cutting tool under different lubrication conditions, at varied cutting velocities. Continuous interaction between tool and work alloy results in severe plastic deformation of the work material; and these deformed material (with passage of times) get adhered at some portions of the tool face, forming an adhesive layer [40]. Traces of material adhesion are noticed at the tool face as shown in Fig. 2. Also, high speed machining aids the material to be adhered in layer by layer (layer wise material adhesion) as exhibited in Fig. 3, corresponding to $v=80 \mathrm{~m} / \mathrm{min}$. Such material adhesion along tool faces, and pressure of high magnitude (arising 
due to machining of difficult-to-cut work alloy) altogether cause deposition of uneven-shaped fused material or Built-Up-Edge (BUE) along the tool nose [41-43]. In Fig. 3, BUE is prominently visible in the micrograph of worn-out insert. Formation of BUE, and adhesive layer, can alter geometry of the cutting tool, and hence, can adversely affect machinability of the work material [36].
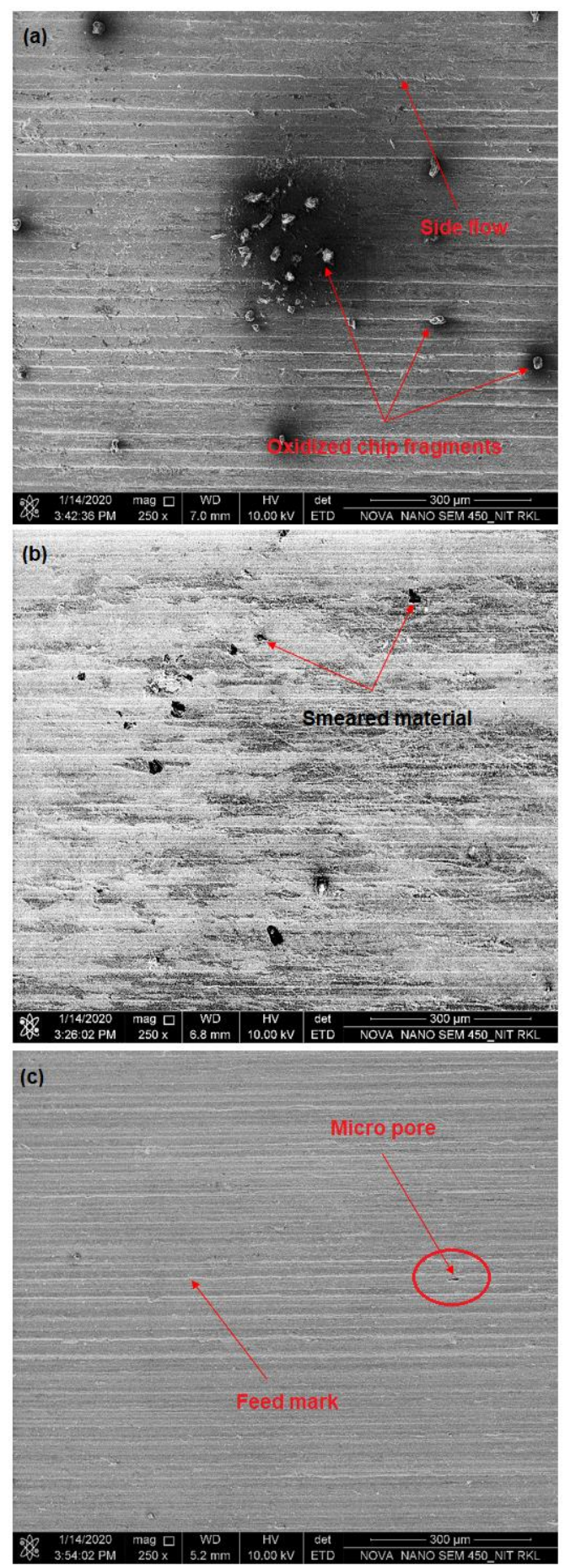

Fig. 1. Micro-morphology of machined surface obtained under (a) Dry machining, (b) Conventional MQL, and (c) NFMQL at $v=80 \mathrm{~m} / \mathrm{min}$.

However, deposition of such adhered material along tool faces restricts smooth sliding of moving chips. Once, in a while, fast-moving chips have a tendency to pluck these materials off from the tool surface, and thus, attrition type wear is incurred. Attrition wear is also noticed herein as exhibited in Fig. 2. However, in Fig. 5, attrition wear, witnessed at the tool flank face, may be caused due to inadequate compaction of tool binder elements which promotes dislodgement of tool substrate material by excessive tool vibration. While machining Ti64 with uncoated carbide insert under various lubrication conditions, similar type of wear was described by Raza et al. [41]. Again, some harder particles trapped (due to strain-hardening of work alloy, and hard carbide inclusions from carbide cutting tool) at tool-work interfacial regions tend to rub against tool flank face, and produce parallel groove-like structures $[42,44]$. These parallel grooves are nothing but severe abrasion marks, and can directly be located on the tool face or along the adhered layers as indicated in Fig. 3 and Fig. 5. Some chunks of material accumulation are also noticed along the peripheral vicinity of cutting edge; which are marked as wear debris (Fig. 3). Formation of such uneven shaped profiles can be elucidates as the deposition/ settlement of harder inclusions at contact zone during severe machining conditions. Also high temperature (at machining sites) associated with the intense pressure, acting at smaller contact area, are responsible for such findings [45]. At $v=50 \mathrm{~m} / \mathrm{min}$, and $v=100 \mathrm{~m} / \mathrm{min}$, it is observed that tiny chips, evolved during machining, get fragmented due to the obstacles (BUEs/ BUL) along their path of motion, and these broken chip fragments remain stuck at some portions of tool surface. The phenomenon is called as chip sticking (Fig. 2, and Fig. 4).

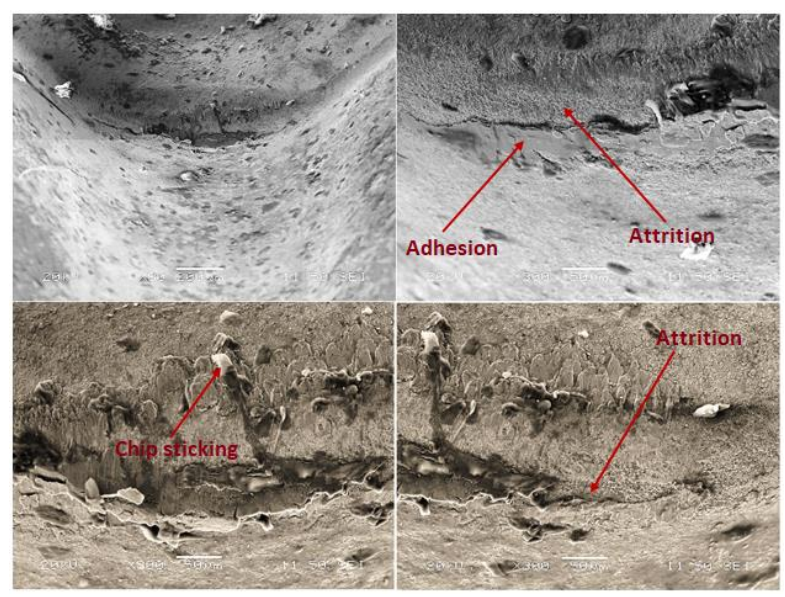

Fig. 2. Wear morphology of tool insert operated at $v=50$ $\mathrm{m} /$ min under NFMQL.

However, an interesting characteristic of MQL/ NFMQL machining is observed at tool flank face at $v$ $=100 \mathrm{~m} / \mathrm{min}$ which is marked as unaffected zone (Fig. 4 ). These unaffected zones refer to those portions of tool surface which remain undamaged by wear modes, depicted in the present study. This distinctiveness can be attributed to the formation of a strong tribo-layer or tribo-film of boundary lubrication at the interfacial junction of tool-work alloy. As compared to MQL machining, unaffected zones are found much prominent for NFMQL machining. Improved tribological properties of nanofluid, due to 2D surface characteristics of graphene powder, and high thermal conductivity 
(when dispersed in based cutting fluid), help to protect the tool surface from suffering any kind of wear modes. Formation of such tribo-film at interfacial regions was also witnessed by earlier researchers during NFMQL machining [25, 36, 43]. The undesirable adverse impression of nanofluid, related to high cutting force at $v=120 \mathrm{~m} / \mathrm{min}$, is reflected in the micrograph of wornout tool insert (Fig. 5a). Lack of nanofluid penetration (into machining sites) and inadequate lubrication favour fast moving chips to undergo severe oxidation in presence of atmospheric oxygen, and fusion over tool rake face, in the vicinity of tool cutting edge. This phenomenon of oxidation is also confirmed through residues of abundant oxygen $(52.37 \%)$ followed by $42.21 \%$ carbon (by weight) as revealed through EDS performed at the fused zone (Fig. 5b).

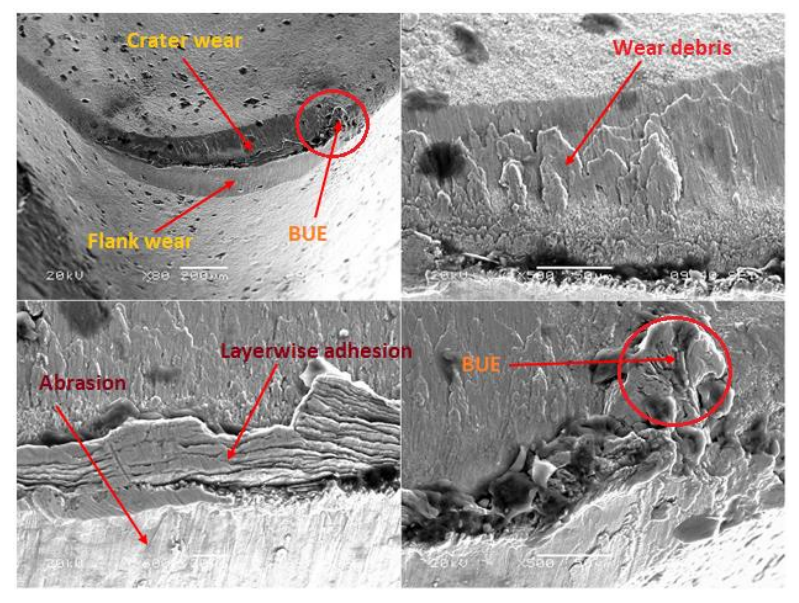

Fig. 3. Wear morphology of tool insert operated at $v=80$ $\mathrm{m} / \mathrm{min}$ under NFMQL.

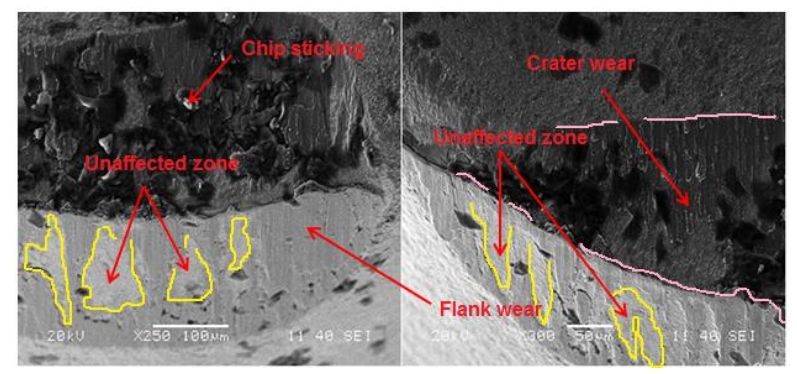

Fig. 4. Wear morphology of tool insert operated at $v=100$ $\mathrm{m} / \mathrm{min}$ under MQL.

During machining, extra work material is removed in the form of chips. Therefore, evolved chips play an important role towards assessing machinability of any work alloy. Specimen chips, collected at extreme cutting velocity $(v=120 \mathrm{~m} / \mathrm{min}$ ), are viewed through optical microscope as well as scanning electron microscope. Optical micrographs of chip specimen, as presented in Figs. 6-7, clearly illustrate serrated/ segmented type of chip formation irrespective of the lubrication condition employed. Such type of chip formation is attributed to catastrophic shear failure of the chips which lays a suitable base for the crack (produced due to severe plastic deformation at the tool-tip) to propagate further, and to form segments on chip surfaces [46]. Deformed shear bands are described by the optical micrograph of the chip (as shown in Fig. 6), collected during dry machining at $v=120 \mathrm{~m} / \mathrm{min}$. In order to understand occurrence of shear failure, the same chip specimen is further viewed under SEM, and studied (Fig. 6). Micrograph reveals that grains at the junction of two consecutive teeth of saw-toothed chip profile get elongated due to shear localization at sever cutting conditions (machining at $v=120 \mathrm{~m} / \mathrm{min}$, under dry condition). Similar observation on shear localization, and chip segment formation were also reported by Joshi et al. [47], during machining of Ti64 alloy with PVD TiAlN coated carbide inserts.

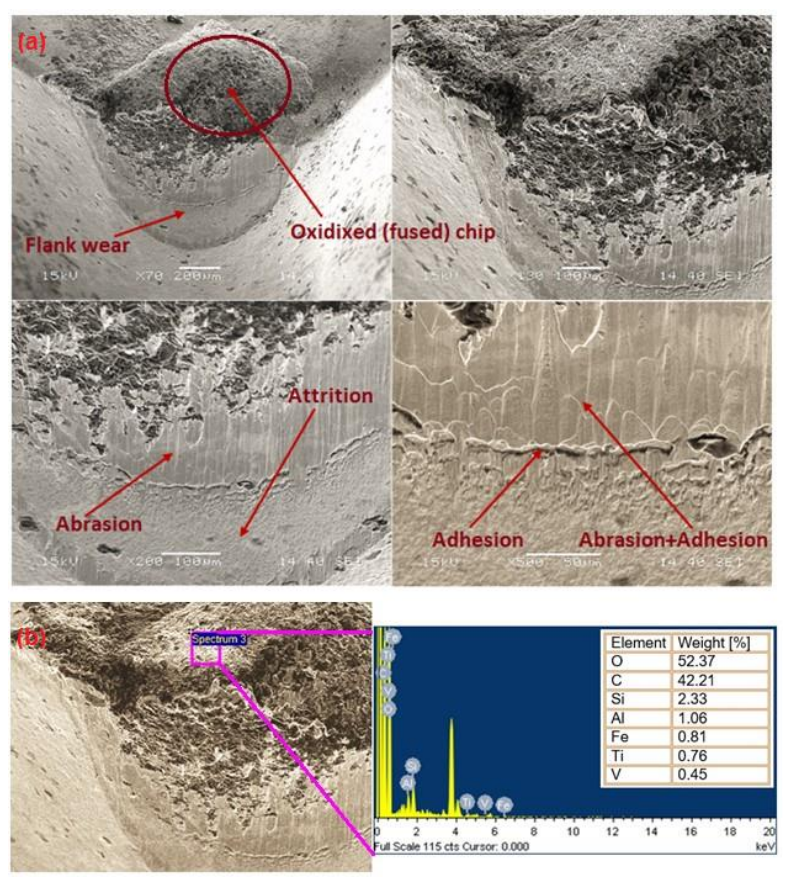

Fig. 5. (a) Wear morphology of tool insert operated at $v=$ $120 \mathrm{~m} / \mathrm{min}$ under NFMQL, (b) constituents of oxidized chip through EDS.

Fig. 7 clearly indicates that the segments formed on the serrated chip profile as observed in case of dry machining are much prominent than nanofluid assisted machining. This confirms intensive shear localization at the primary shear zone due to inadequate cooling (imposed by dry cutting environment) which causes more heat to be accumulated at the tool-chip interface causing a secondary shear layer formation at the bottom of chip samples. Thickness $(\delta)$ of this secondary shear layer is measured separately for both dry machining $(\sim 3.421 \mu \mathrm{m})$ and NFMQL $(\sim 0.89925 \mu \mathrm{m})$ conditions. For NFMQL machining, formation of thinner secondary layer can be attributed to the lesser tool-chip interfacial temperature at due to effective cooling and lubrication properties of nanofluids [48]. The angle of inclination of shear planes with respect to the vertical axis provides the value of shear angle for the collected chip specimens. A wider angle of shear $\left(\sim 50.56^{\circ}\right)$ is found for the chips collected during NFMQL machining while dry cutting results in an average shear angle of $45.018^{\circ}$. Rise in shear angle under nanofluid assisted machining is due to effective penetration of coolant into core machining zones and thereby, reduced magnitude of cutting force [49]. 


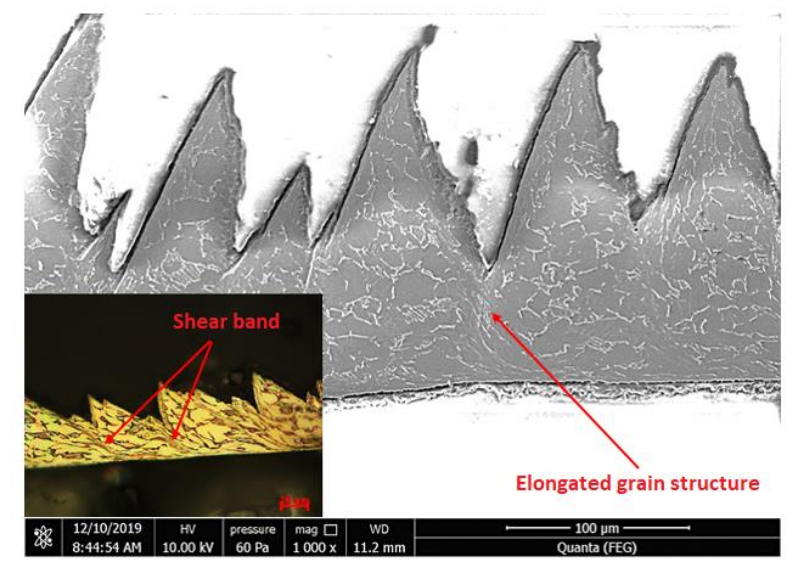

Fig. 6. Adiabatic shear band: Specimen chip collected at $v=$ $120 \mathrm{~m} / \mathrm{min}$ under dry condition.

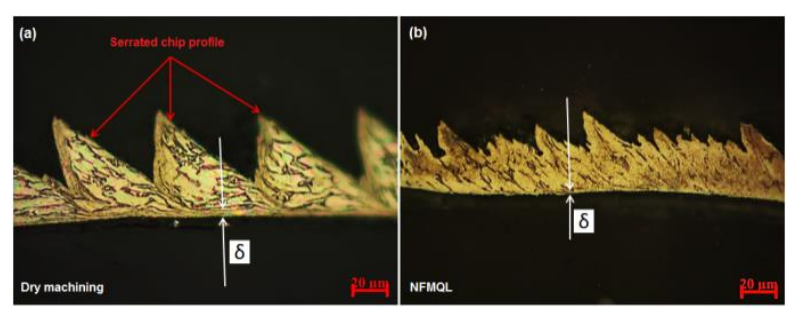

Fig. 7. Saw-toothed serrated chip profile: Specimen chip obtained at $v=120 \mathrm{~m} / \mathrm{min}$ under (a) dry machining and (b) NFMQL.

\section{Conclusions}

The conclusions from the above experimental work are summarized below.

1. The integrity of machined surface declares effectiveness of biodegradable vegetable oil as MQL coolant (with/ without nano-additives) when compared to dry machining. Again, application potential of 2D layered-structured graphene nanoplatelets (NFMQL) is understood by observing the smoothest machined surface (amongst all lubrication conditions) without any noticeable defects.

2. Though adhesion, attrition, abrasion, chip sticking are found to be the prominent modes of tool wear under MQL/ NFMQL machining; but generation of tribo-film assures proper penetration of coolant jet into the interfacial regions (tool-work) and hence, progression of tool wear is reduced comparatively.

3. The chips produced during machining process are of segmented/ serrated type; the cause of which can be attributed to the intensive shear localization on the chip surfaces due to machining induced heats at different deformation zones. This heat localization is, however, responsible for elongation of grains, and production of shear bands along serration profiles.
4. A thicker secondary shear layer $(\sim 3.421 \mu \mathrm{m})$ and narrower shear angle $\left(\sim 45.018^{\circ}\right)$ in case of dry machining clearly illustrate industrial requirements of MQL/ NFMQL systems for better chip control, desired surface quality and enhanced machinability of difficult-to-cut work alloys.

\section{References}

1. E.O. Ezugwu, J. Bonney, Y. Yamane, J. Mater. Proc. Technol. 134, 233 (2003)

2. X. Liu, P.K. Chu, C. Ding, Mater. Sci. Eng. 47, 49 (2004)

3. E. Kuljanic, M. Sortino, G. Totis, International Research/Expert Conference Trends in the Development of Machinery and Associated Technology, Mediterranean Cruise, 1 (2010).

4. P.A. Dearnley, A.N. Grearson, Mater. Sci. Technol. 2, 47 (1986)

5. J.M. Gerez, M. Sanchez-Carrilero, J. Salguero, M. Batista, M. Marcos, AIP Conference proceedings, American Institute of Physics, 1181, 567 (2009)

6. M. Álvarez, A. Gómez, J. Salguero, M. Batista, M.M. Huerta, M. Marcos Bárcena, Adv. Mater. Res. 107, 77 (2010)

7. M. Armendia, A. Garay, L.M. Iriarte, P.J. Arrazola, J. Mater. Proc. Technol. 210, 197 (2010)

8. N. Khanna, K.S. Sangwan, Int. J. Precision Eng. Manuf. 14, 719 (2013)

9. X. Zhang, R. Shivpuri, A.K. Srivastava, International Manufacturing Science and Engineering Conference, 1 (Charlotte, North Carolina, USA, 56826, 2015) pp..

10. F. Klocke, G. Eisenblatter, Keynote papers. Opening session of Dry Cutting, Annals of CIRP, 46, 519 (1997)

11. N. Narutaki, A. Murakoshi, S. Motonishi, H. Takeyama, CIRP Annals, 32 , 65 (1983)

12. N. Muthukrishnan, P. Davim, J. Surf. Engineered Mater. Adv. Technol. 1, 9 (2011).

13. L.J. Lazarus, Costs Associated with the Use of Metalworking Fluids. Metalworking Fluids, 463481 (CRC Press, (2017)

14. R.S. Revuru, N.R. Posinasetti, V.R. VSN, M. Amrita, Int. J. Adv. Manuf. Technol. 91, 2477 (2017)

15. K.D. Rosenman, Current Opinion in Allergy and Clinical Immunology, 9, 97 (2009)

16. J.P. Byers, Metalworking fluids, CRC Press, 2016.

17. D. Setti, M.K. Sinha, S. Ghosh, P.V. Rao, Int. J. Machine Tools Manuf. 88, 237 (2015).

18. V.S. Sharma, G. Singh, K. Sørby, Mater. Manuf. Proces. 30, 935 (2015)

19. Y. Songmei, H. Xuebo, Z. Guangyuan, M. Amin, Advances Prod. Eng. Management, 12, 139 (2017) 
20. S.N. Rao, B. Satyanarayana, K. Venkatasubbaiah, Int. J. Eng. Sci. Technol. 3, 2928 (2011)

21. S. Prabhu, B.K. Vinayagam, Int. J. Adv. Manuf. Technol. 60, 149 (2012)

22. S. Roy, A. Ghosh, International Manufacturing Science and Engineering Conference, American Society of Mechanical Engineers, June 10-14, 2013, Madison, Wisconsin, USA, 55461 1-6. (2013)

23. P. Sharma, B.S. Sidhu, J. Sharma, Journal of Cleaner Production, 108, 72 (2015).

24. S. Paul, A.K. Singh, A. Ghosh, Mater. Manuf. Proces. 32, 608 (2017)

25. H. Hegab, H.A. Kishawy, M.H. Gadallah, U. Umer, I. Deiab, Int. J. Adv. Manuf. Technol. 97, 1593 (2018)

26. N.K. Sahu, A.B. Andhare, R.A. Raju, Machining Sci. Technol.: an Int. J. 22, 476 (2018)

27. J. Samuel, J. Rafiee, P. Dhiman, Z.Z. Yu, N. Koratkar, The Journal of Physical Chemistry C, 115, 3410 (2011)

28. A. Uysal, Industrial Lubrication and Tribology, 68, $446(2016)$

29. S. Yi, N. Li, S. Solanki, J. Mo, S. Ding, Int. J. Adv. Manuf. Technol. 103, 1481 (2019)

30. Y.M. Shashidhara, S.R. Jayaram, Advances in Tribology, 1 (2013)

31. N. Talib, E.A. Rahim, Procedia CIRP, 40, 504 (2016)

32. S. Bilal, M. Nuhu, S.A. Kasim, J. Chem. Eng. Mater. Sci. 4, 72 (2013)

33. K. Sarker, Int. J. Eng. Technol. 71,965 (2016)

34. S.S.N. Azman, N.W.M. Zulkifli, H. Masjuki, M. Gulzar, R. Zahid, J. Mater. Res. 31, 1932 (2016)

35. T. Lv, S. Huang, E. Liu, Y. Ma, X. Xu, J. Manuf. Proces. 34, 225 (2018)

36. M. Jamil, A.M. Khan, H. Hegab, L. Gong, M. Mia, M.K. Gupta, N. He, Int. J. Adv. Manuf. Technol. 102, 3895 (2019)

37. A. Ginting, M. Nouari, Int. J. Machine Tools Manuf. 49, 325 (2009)

38. M. Mia, M.A. Khan, N.R. Dhar, Int. J. Adv. Manuf. Technol. 90, 1825 (2017)

39. D. Ulutan, T. Ozel, Int. J. Machine Tools Manuf. 51, 250 (2011)

40. R.B. da Silva, Á.R. Machado, E.O. Ezugwu, J. Bonney, W.F. Sales, J. Mater. Proc. Technol. 213, 1459 (2013)

41. S.W. Raza, S. Pervaiz, I. Deiab, Int. J. Precision Eng. Manuf. 15, 1979 (2014)

42. S. Pervaiz, A. Rashid, I. Deiab, C.M. Nicolescu, Int. J. Adv. Manuf. Technol. 87, 1371 (2016)

43. Chetan, B.C. Behera, S. Ghosh, P.V. Rao, Tribology Int. 101, 234 (2016)

44. S. Sun, M. Brandt, J.P. Mo, Proc. IMechE, Part B: J. Eng. Manuf. 228 , 191-202 (2014)
45. F. Halila, C. Czarnota, M. Nouari, Mater. Sci. Forum, 763, 65 (2013)

46. M. Cotterell, G. Byrne, CIRP Annals, 57, 93 (2008)

47. S. Joshi, A. Tewari, S. Joshi, J. Manuf. Sci. Eng. 135, 1 (2013)

48. A. Aramcharoen, Procedia CIRP, 46, 83 (2016)

49. Shyha, S. Gariani, M.A. El-Sayed, D. Huo, Metals, 8, 185 (2018) 